\title{
The Influence of Substrate to Larval Settlement of the Tropical Abalone (Haliotis asinina)
}

\author{
Hadijah, S. Budi ${ }^{1} \&$ Zainuddin E. Viky ${ }^{1}$ \\ ${ }^{1}$ Department of Fisheries Faculty of Agriculture, University of "45" Makassar, Indonesia \\ 2 Department of Fisheries Faculty of Marine Sciences and Fisheries, Hasanuddin University, Makassar, \\ Indonesia \\ Correspondence: Hadijah, S. Budi, Department of Fisheries Faculty of Agriculture, University of "45" Makassar, \\ Indonesia. E-mail: hadijahmahyuddin@yahoo.com
}

Received: July 29, $2014 \quad$ Accepted: August 10, $2014 \quad$ Online Published: December 29, 2014

doi:10.5539/mas.v9n1p184 URL: http://dx.doi.org/10.5539/mas.v9n1p184

\begin{abstract}
Larval settlement stage of abalone (Haliotis asinine) depends on availability of feed and substrate compatibility. Existing feed size and feed type diversity in substrate will affect larval settlement stage, feeding habit and survival rate of abalone larvae. This study aims to find out the most suitable substrate for larval settlement of the tropical abalone. It is conducted in February-April, 2013 at Brackish Water Aquaculture Center, Takalar Regency, South Sulawesi. Applied experimental design is Completely Randomized Design. There are 3 types of test substrate: coral, cement and plastic with 3 replications for each substrate. This study shows that statistically, substrate differences do not affect to larval settlement stage. The highest stage of larval settlement is to coral substrate by $3.3 \%$, followed by cement and plastic by $2.2 \%$ and $0.2 \%$ respectively. The highest average stage of living larva on coral and cement substrate are $15.3 \%$, while on plastic substrate is $8.7 \%$.
\end{abstract}

Keywords: substrat, larval settlement, tropical abalone, Haliotis asinine

\section{Introduction}

Tropical abalone (Haliotis 184sinine) is one of aquatic biological resources from coral reef with high economic value. Abalone belongs to export commodity with high price either for its meat or eggshell. This shell is very popular in other countries such as Japan, US, European countries, Columbia and Canada because of its delicious meat and low cholesterol level. Indeed, in Japan, New Zealand and Philipine, this shell has been cultivate (Kijima, et al., 2002 and Litaay et al., 2001).

Abalone seeding effort has been developed, but its survival rate is still low of about 10-15\% (William et al., 2008). Environmental factor (Baldwin et al., 2007 and Hadijah et al., 2013), feed type and size diversity (Chen and Chen, 2000) belong to determinant factors of abalone survival rate. At larval stage, substrate difference will affect growth rate (Bautista, 2003). Williams et al., (2008) states that the success rate of larvae in the process of settlement is determined by the substrate in the growth medium (Williams., et al, 2008).

Larval settlement speed of abalone depends on availability of feed and substrate compatibility (Alle., et al,. 2006). However, larval settlement of the tropical abalone (H. 184sinine) to different substrate has not been widely reported, especially those with seed parents from Tanakeke Islands, Takalar.

Therefore did not already know the existence and potential of local parent who can serve as a source of stem for seeding purposes of abalone in South Sulawesi.

\section{Research Method}

\subsection{Research Schedule and Site}

This study is conducted in February-April, 2013 at abalone hatchery of Brackish Water Aquaculture Center, Takalar Regency, South Sulawesi.

\subsection{Research Material}

Used container in this study is 12 plastic containers with the size of 50x40x30 cm and they are provided with aeration equipments. Used test animal is 1200 Haliotis asinins larvae at the age of 0 day and 0.1-0.5 mm length. 
In order to grow up natural feed Nitzchia sp., $\mathrm{Na}_{2} \mathrm{SiO}_{3}, \mathrm{KNO}_{3}$ and $\mathrm{Na}_{2} \mathrm{HPO}_{4}$ are used.

\subsection{Research Procedure}

Larvae are spread in cultivation container with density of 100 larvae/container by means of flowing water system and aeration. Larval feed Nitzchia sp are spread in two weeks before larval spreading. Here is how the fertilizer is prepared: Solution I, $200 \mathrm{ml}$ of Silicate $\left(\mathrm{Na}_{2} \mathrm{~S}_{\mathrm{i}} \mathrm{O}_{3}\right)$, is dissolved in 5 liter of distilled water and then stirred to make it completely dissolved. Solution II, $\mathrm{KNO}_{3}=800$ gram, $\mathrm{Na}_{2} \mathrm{HPO}_{4}=250$ gram and Clewat $32=80$ gram, are dissolved in 10 liter of distilled water and stirred to make them completely dissolved. Next, material as larval settlement place is arranged into treatment container. Hatched larvae (veliger) are taken care for 1 month until they are $1 \mathrm{~cm}$ length. When day 11 comes, circulation is given to larval cultivation medium. During this cultivation, larvae are only fed by natural feed Nitzschia sp.

\subsection{Design of Experiment and Data Analysis}

This study is designed based on completely randomized design with 3 treatments and 3 replications. Observed treatments uses different substrate, they are: (A) coral, (B) cement and (C) plastic. Collected data in this study is larval settlement stage to the substrate and survival of abalone larva. Larval settlement to substrate is counted by applying NRC formulation (1977) as follow:

$$
L P(\%)=\frac{N o}{N t} \times 100 \%
$$

Description:

SR: Settlement Rate (\%)

$\mathrm{Nt}$ : Amount of settlement abalone larva in the final of study (number of larva)

No.: Amount of settlement abalone larva in the initial of study (number of larva)

In this study, all of the research finding are presented in average value. Data is analyzed by applying Variant Analysis (ANOVA) through SPSS Program version 16.0 to determine the existence of differences at inter-treatment. Statistically, it is considered as significant if $\mathrm{P}<0.05$ (Steel and Torrie, 1982).

\section{Research Findings and Discussion}

\subsection{Abalone Larval Settlement}

Research finding by using substrate as larval settlement medium of the tropical abalone (Haliotis asinine) by the age of 0 day up to the settlement stage shows settlement difference although it uses similar feed dose for each treatment $(3000 \mathrm{ml})$. Result of variant analysis shows that there is no effect of larval settlement to the substrates $(\mathrm{P}>0.05)$. Based on this finding, average value of larval settlement of the tropical abalone (Haliotis sinine) can be seen in the following figure.

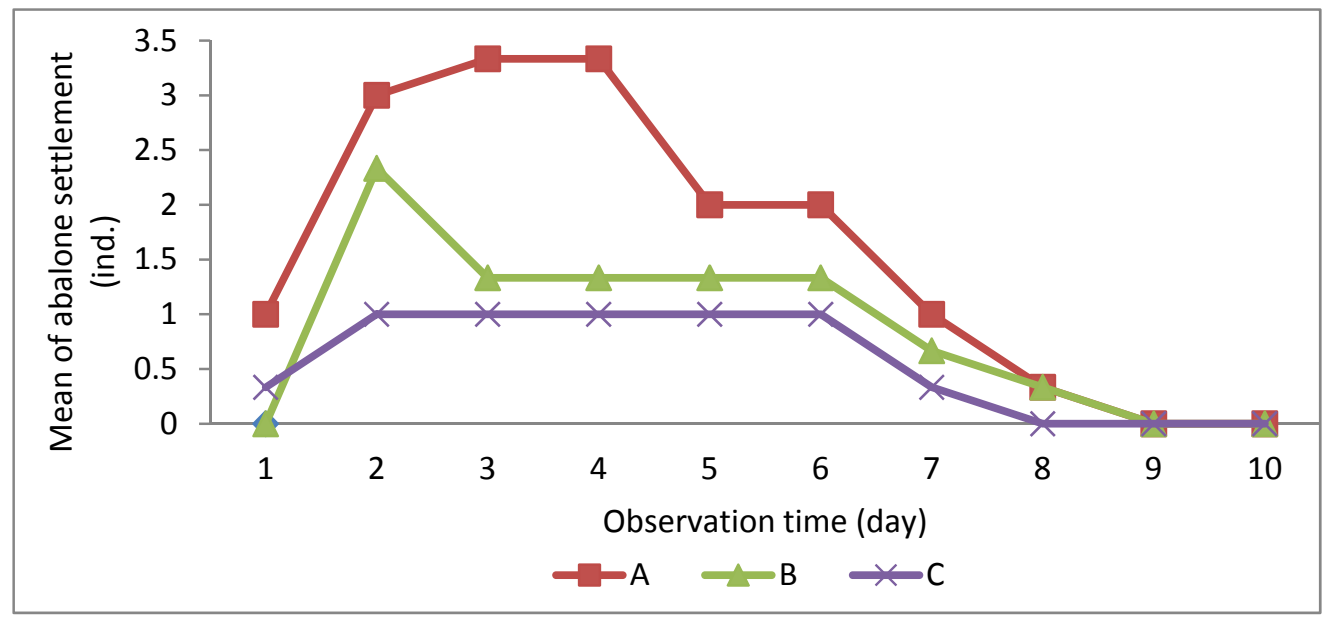

Figure 1. Larval settlement of abalone in each treatment

Figure 1 shows that average rate of abalone larval settlement (Haliotis asinine) in each treatment reaches the 
highest rate in treatment $\mathrm{A}$, i.e., coral substrate by average value of settlement rate $3.3 \%$. Then, it is followed by treatment $\mathrm{B}$ cement and treatment $\mathrm{C}$ wave plastic by average value of 2.2 and 0.2 respectively. Based on the finding, it is seen that every treatment has different amount of settlement whether to coral, cement or iron plastic substrate.

Result of variant analysis shows that there is no obvious effect of larval settlement to the substrates $(\mathrm{P}>0.05)$. Follow up tuckey test in each treatment shows that larval settlement degradation rate to the substrate in all treatments do not obviously give an effect $(\mathrm{P}>0.05)$.

The greatest amount of abalone larval settlement is in treatment A on day 2, day 3 and day 4, which is attached to coral substrate with 5 tails of each coral. Then, it is followed by treatment B on day 2 with 3 tails to each substrate, while treatment $\mathrm{C}$ reaches its greatest amount on day 2 with 2 larvae. Lack of larval settlement to the substrate is caused by lack of handling way toward those larvae. It is also caused by low survival rate of the larva in each treatment.

This finding is also supported by statement of William, 2008 stating that abalone seeding effort has been developed, but its survival rate is still low of about 10-15\% (Williams., et al, 2008). Environmental factor (Hadijah, et al., 2013), feed type and feed size (Gullardo and Buen, 2003: Setyono, 2007) are determinant factors for abalone seeding success rate.

At larval stage, substrate difference will affect abalone growth stage (William et al., 2008). Speed rate of larval settlement of abalone depends on availability of feed and substrate compatibility (William et al., 2008). Existing feed type and feed size diversity on substrate will affect larval settlement, feeding habit and survival rate of abalone larva (Allen., et al, 2006).

Therefore, it can be concluded that survival rate of larva produced from seeding effort is quite low as stated by Allen et al., (2006). He states that survival rate of abalone larva is too low of about 0.6-1.00\% (Allen., et al, 2006). Allegedly, when abalone larva is at trochophore and veliger stage, mass death is occurred which causes low level of abalone survival rate. It might also cause by availability of natural feed in its early growth medium, environmental condition, cultivation medium, feed size and feed type and also lack of control to larval growth in cultivation container.

\subsection{Survival Rate}

Finding on effect of different substrate to larval settlement of the tropical abalone (Haliotis asinine) shows different amount of living larva at each treatment. Calculation of abalone larva at each treatment to different substrate toward larval survival rate does not show any obvious effect $(\mathrm{P}>0.05)$. Average survival rate of abalone larva living in each treatment can be seen in appendix 1, while average survival rate of the larva can be seen in the following Figure 2:

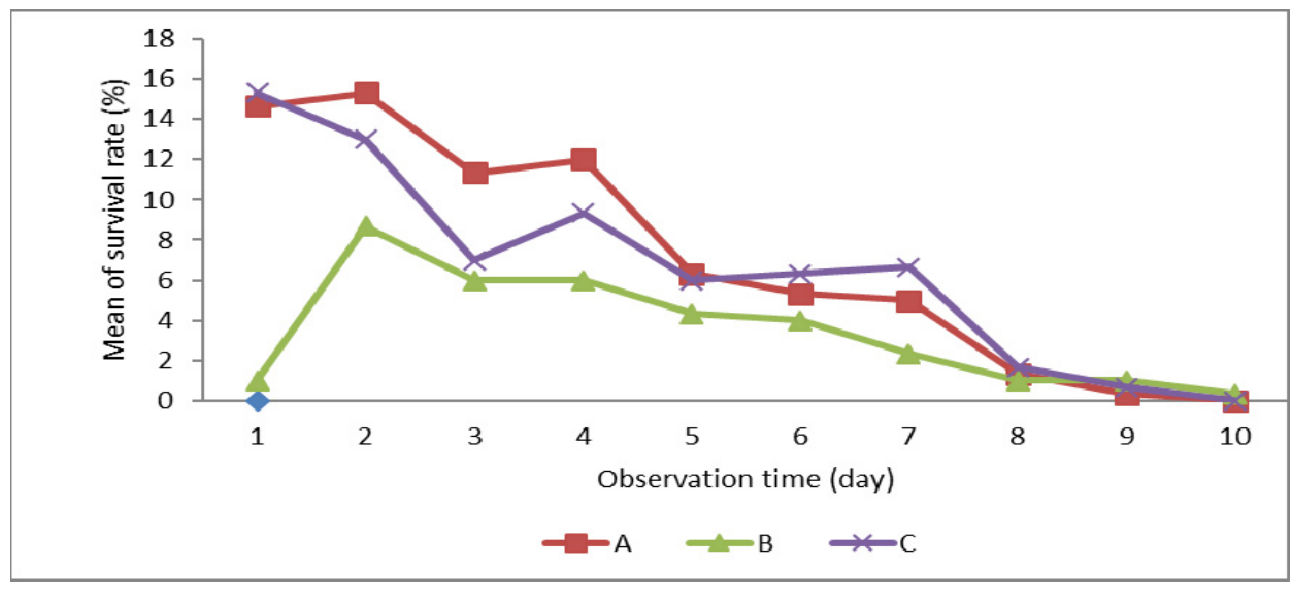

Figure 2. Amount of living abalone larva in each treatment

The greatest average amount of living abalone in each treatment to the coral, cement and iron plastic is in treatment $\mathrm{A}$ and $\mathrm{C}$ by average amount of 15.3, and it is followed by treatment $\mathrm{B}$ to wave plastic substrate by living average amount of 8.7 . 
High amount of abalone larva (Haliotis asinine) living in treatment A on coral substrate is caused by availability of sufficient feed either for its size, amount and its natural habitat by attaching to the coral as supported by Setyono (2005). The existing feed type and feed size diversity will affect larval settlement, feeding habit and survival rate of abalone larva (Setyono, 2005).

The finding (Kawamura et al, 2002), shows sediment effect to larval settlement of the tropical abalone (Haliotis diversicolor). Most of abalone larva lives on rocky substrate and coral. Speed rate of larval settlement of abalone depends on availability of feed and substrate compatibility (William et al., 2008; Maliao., 2004). Existing feed type and size diversity on substrate will affect larval settlement, feeding habit and survival rate of abalone larva (Setyono, 2005).

Most of abalone diseases come from water which is used in the seeding process. Based on analysis conducted by Brackish Water Aquaculture Center Takalar, one causal diseases of abalone come from vibrio, a bacteria type. On the other hand, William, et al., (2008) states that appropriate substrate for tropical abalone larva is corallinales type from Amphiora sp species (William et al., 2008).

\subsection{Water Quality}

Measurement on water quality during the study shows that the existing water quality parameter in Brackish Water Aquaculture Center is proper to be used. Range value on water quality parameter during the study can be seen in table 4 as follows:

Table 1. Water Quality Parameter of Abalone Larva (H. sinine)

\begin{tabular}{clcc}
\hline No. & \multicolumn{1}{c}{ Parameter } & Unit of Measurement & Average Value \\
\hline 1. & Salinity & $\mathrm{ppt}$ & 30 \\
2. & Temperature & ${ }^{\circ}$ & $28-29$ \\
3. & DO & $\mathrm{mg} / 1$ & $3-7$ \\
4. & $\mathrm{pH}$ & - & 7 \\
5. & Ammonia & $\mathrm{ppm}$ & $<>$ \\
6. & Brightness & $\mathrm{M}$ & $>10$ \\
\hline
\end{tabular}

\section{Conclusion and Suggestion}

\subsection{Research Conclusion}

Based on research finding on tropical abalone larva (H. asinina), it can be concluded that:

1. Success rate of abalone seeding effort, especially the settlement is determined by seed parents quality, feeding management, water quality management and pest and disease control.

2. Water quality parameter for abalone shells seeding is of $\mathrm{pH} 7-8$, temperature at $28-29^{\circ} \mathrm{C}$, water salinity at 30 ppt and DO at 3-7 ppm.

3. Average rate of larval settlement to substrate does not show any obvious effect at each treatment.

\subsection{Research Suggestion}

In order to ensure seeding success rate in abalone cultivation, cultivation medium should be highly cared for.

\section{References}

Allen, V. J., Marsden, I. D., Ragg, N. L. C., \& Gieseg, S. (2006). The effects of tactile stimulants on feeding, growth, behaviour, and meat quality of cultured Blackfoot abalone, Haliotis iris. Aquaculture, 257, $294-308$. http://dx.doi.org/10.1016/j.aquaculture.2006.02.070

Baldwin J., Elias, J. P., Wells, R. M. G., \& Donovan, D. A. (2007). Energy metabolism in the tropical abalone, Haliotis asinina Linné: Comparisons with temperate abalone species. Journal of Experimental Marine Biology and Ecology, 342, 213-225. http://dx.doi.org/10.1016/j.jembe.2006.09.005

Bautista-Teruel, M., N., Fermin, A. C., \& Koshio, S. S. (2003). Diet development and evaluation for juvenile abalone, Haliotis asinina: Animal and plant protein sources. Aquaculture, 219, 645-653. http://dx.doi.org/10.1016/S0044-8486(02)00410-6

Chen, J. C., \& Chen, W. C. (2000). Salinity tolerance of Haliotis diversicolors upertexta at different salinity and temperature levels. Aquaculture, 181, 191-203. http://dx.doi.org/10.1016/S0044-8486(99)00226-4 
Gallardo, W. G., \& Buen, S. M. A. (2003). Evaluation of mucus, Navicula, and mixed diatoms as larval settlement inducers for the tropical abalone Haliotis asinina. Aquaculture, 221, $357-364$. http://dx.doi.org/10.1016/S0044-8486(03)00121-2

Hadijah, A., Tuwo, M., Litaay, \& Indrawati, E. (2013). The reproductive Aspect of Tropical Abalone (Haliotis asinine L.) in The Waters of tanakeke Islands at South Sulawesi. Aquatic Science and Technology, 1(2), 30-43. http://dx.doi.org/10.5296/ast.v1i2.3721

Kawamura, T., Takami, H., \& Saido, T. (2002). Early Life Ecology of Abalone Haliotis discus hannai in Relation to Recruitment Fluctuations. Fisheries Science, 68, 230-233.

Kijima, A., Qi, L., \& Park, C. (2002). Development of Genetics and Breeding in Abalone Culture. Fisheries Science, 68, 730-733.

Litaay, M., \& De Silva, S. S. (2003). Spawning season, fecundity and proximate composition of the gonads of wild-caught blacklip abalone (Haliotis rubra) from Port Fairy waters, south eastern Australia. Aquat. Living Resour, 16, 353-361. http://dx.doi.org/10.1016/S0990-7440(03)00067-6

Maliao, R. J., Webb, E. L., \& Jensen, K. R. (2004). A survey of stock of the donkey's ear abalone, Haliotis asinina L. in the Sagay Marine Reserve, Philippines: Evaluating the effectiveness of marine protected area enforcement. Fisheries Research, 66, 343-353. http://dx.doi.org/10.1016/S0165-7836(03)00181-4

Setyono, D. E. D. (2005). Abalon(Haliotis asinine L): 4. Embryonic and Larva Develooment. Oseana, XXX(1).

Steel, RGD, \& Torrie, J. H. (1982). Principle and Procedures of Statistics, A Biometrical Approach. Second edition. Florida: CRC Press.

Williams, E. A., Craigie, A., Yeates, A., \& Degnan, S. M. (2008). Articulated Coralline Algae of the Genus Amphiroa Are Effective Natural Inducers of settlement in The Tropical Abalone Haliotis asinina. The Biological Bulletin, 215, 98-107. Marine Biological Laboratory. Academic Research Library. http://dx.doi.org/10.2307/25470687

\section{Copyrights}

Copyright for this article is retained by the author(s), with first publication rights granted to the journal.

This is an open-access article distributed under the terms and conditions of the Creative Commons Attribution license (http://creativecommons.org/licenses/by/3.0/). 